\title{
守护心理健康 助力学生成长
}

马英

湖北省洪湖市第一中学

DOI:10.32629/jief.v2i8.2124

[摘要] 2020 年的新冠肺炎疫情无疑给面临高考激烈竞争的高三学生增添了巨大压力。学生们不能像从前一样在学校里备战高考, 而只能宅 在家里上网课, 特别是那些平时自律性较差的学生, 面对高考与疫情的双重压力、期望与现状的巨大落差, 难免产生恐慌、焦虑不安, 有的 甚至十分痛苦。如何让处于这一特殊时期的高三学生克服负面情绪, 积极备战高考? 如何让学生接受现实并调整好自己的情绪, 实现弯道超 越, 逆袭高考? 这是每一个高三教师需要重点关注的十分重要的问题。

[关键词] 心理健康; 助力成长; 分析

中图分类号: G633.2 文献标识码: A

作为高三年级班主任的我, 应用自己习得的心理健康教育知识, 借 助微信、QQ 群, 钉钉, 抖音短视频等现代通讯手段, 及时了解每个学生 心理状态, 认真做好心理疏导, 提高学生心理素质, 促进学生健康成长, 让他们积极、乐观地面对 2020 高考。

\section{1 树立一种理念----一心理健康是学生复习备考的前提}

因为新冠疫情影响, 高中开学时间不断推迟, 加上高三学生原本存 在的高考前情绪不稳、心理承受能力低、缺乏自信、考试焦虑、青春期 闭锁心理等不健康的心理状态, 给高三学生复习备考带来诸多困难。如 果这种状况不能得以缓解, 学生可能难以走出心理困扰, 心理情绪问题 的表现或许会更为突出。因此, 进行及时、必要、有针对性的心理援助 和心理疏导, 为学生创设一个和谐、健康、充满活力的居家学习氛围, 提高高考复习效率便显得尤为重要。

为此, 我不仅在思想上高度重视学生在疫情期间的心理问题, 在行 动上也通过加强心理健康知识教育、传授心理调节方法、营造积极的心 理氛围、构建家校联运机制、开展个体心理咨询等方式，让 “宅家” 复 习、身心处于高度疲累状态的学生从紧张焦虑的负面情绪中逐步解脱出 来，在老师的指导下，有计划、高效率地开展复习备考。

\section{2 弄清两个问题-----学生心理困惑的表现及其原因}

要做好学生的心理援助和心理疏导, 提高心理健康教育的针对性, 必须首先弄清学生心理困惑的表现及其原因。为此, 我通过与学生电话、 短信、微信交流, 发现学生在疫情防控期间的主要心理问题表现在以下 几方面:

一是认知上恐慌。由于通过多种媒体了解到疫情相关新闻和真假难 辩的消息而无法对疫情进行科学的判断, 从而出现社会上出现了灾难、 瘟疫等方面的想法。

二是情绪上焦虑。在日常学习和生活中, 出现无聊、烦躁、憋屈、 消沉、抑郁、易怒、恐惧、焦虑等各种不同的情绪困扰。
三是行为上懈急。生活中无所事事, 学习上不思进取, 自律性变差, 懒于学习、不思读书, 沉迷手机游戏、网络电视等。

四是人际交往上困扰。人际交往范围变窄, 缺少同伴交往, 交往欲 望和交往能力下降，不愿意与家人交流、甚至与家人争吵等。

五是躯体上的不良反应。出现无明显原因的疼痛问题、消化系统问 题、饮食问题和睡眠问题，或过度关心自己的身体症状或出现反复洗手、 消毒等行为。

在上述五类表现中, 以情绪上焦虑和行为上懈急表现最为突出, 占 比也最大。究其原因, 则主要为以下几种: 第一是学习环境的变化, 以 前都是在学校集中学习, 有老师的监督与管理, 而现在是在家里学习, 若家长督促管理不到位, 学习上就容易出现松解表现; 第二是高考压力 大与复习资料时间紧、学习任务繁重与居家学习效率低等多种矛盾叠加, 容量增加学生焦虑、恐愔情绪; 第三是学生及家长的高期望与现实的冲 突, 导致学习上、人际关系的困扰增多; 第四是长时间在疫情阴影下, 生活空间的缩小, 没有任何心理准备、与外人隔绝的居家生活, 确实会 给学生及家长带来紧张恐慌的心理和认知、情绪、行为方面不良反应。

\section{3 采取多种措施----做好学生心理疏导工作}

在弄清学生心理困惑的表现及其原因的基础上, 我结合心理健康教 育的基本理论和自身多年心理辅导的实践，重点开展了以下几方面的工 作。

3.1 营造积极心理氛围

心理健康教育的目的不仅是给学生传授心理健康知识, 更重要的是 为学生创造一个自由、愉悦的心灵空间。我通过召开视频班会、给学生 写公开信 (见附件)、与学生个别交流等方式, 努力让学生明白: “你们 是不平凡的一代人, 生于非典, 考于疫情。现在你们正在经历着自 1977 年恢复高考以来 43 年间最不寻常的高三寒假！对于你们而言, 注定难 忘。” 在疫情压力下可能会出现焦虑、恐慌、愤怒和烦躁等各种不良情绪, 
这是人面对应激事件的正常心理反应, 不必过于敏感和紧张。只要我们 有更强大的意志力、永不放弃的决心、自觉自愿的学习态度和勤学苦练 的拼搏精神, 十二年寒窗苦读, 就会圆梦在今朝。隔着屏幕, 文字、话 语带着共情和支持, 在化解学生的焦虑烦躁情绪的同时, 一个积极健康 的心理氛围已经形成。

3.2 传授心理调节方法

在线上教学、主题班会、与学生个别交流等多个场合, 我都尽可能 地教学生掌握一些简单的心理调节方法, 如 “深呼吸放松法” “蝴蝶拍” “肌肉放松法” 等, 或用运动、音乐、倾诉来转移注意力, 增加积极体验。 同时教育学生通过权威媒体了解防疫防控相关信息, 防止由于过多的信 息或虚假的信息给学生带来的不必要的自我恐慌。

\section{3 建立家校联动机制}

心理治疗专家佩施基安指出: “疾病不仅仅是病人本身的问题, 也反 映了家庭与社会问题。” 同时他也强调家庭在消除心理困扰中的作用: 一 个家庭里实际的和赋予的东西, 绝不仅仅是障碍和冲突, 这个家庭同时 也拥有解决冲突的能力。在这个非常时期, 学生和家长天天 “宅” 在一 起, 如果不能发挥家长的作用, 要想做好学生的心理健康工作是不可能 的。于是, 我从三个方面着手, 建立起良性的家校联动机制。

一是给学生和家长写公开信。针对高中生遇到一些共性的问题（如 学习负担重、心理压力大、父母期望高等), 我在班里微信群里给学生与 家长写信 (见附件), 写对学生的学习要求, 帮助学生调整好自己的心情, 让学生在疫情中依然保持阳光的心态; 写对家长的建议, 帮助家长消除 惶惶不可終日的痛苦心理, 让家长拥有一颗平常的心态。学生和家长读 了我信后, 觉得收获很大, 很多和我分享了他们读后的感想。

二是召开家长学生共同参加的视频班会。在班上的钉钉群里开家长 学生主题班会会六次, 每次会议一个主题, 同时兼顾其他内容, 会上有 老师发言、家长发言、学生发言。会议一方面对学生、对学生家长开展 心理教育活动, 讲解心理健康的基本知识和心理调适的基本方法; 另一 方面讲解家长怎样激励和监管孩子在家高效学习, 帮助学生培养良好的 居家学习习惯; 同时也提醒学生及家长, 要化危为机, 把握疫情防控中 的教育契机, 加强家长与学生的沟通, 密切家长与学生的和谐关系。

三是利用书信与家长交流。为更准确地了解学生个体的情况, 提高 教育的针对性, 在疫情防控的特殊时期, 我要求每位家长与学生共同完 成一封家书发给我, 告知学生居家学习的基本情况、各科复习情况、学 习主动性、学习困难、心理困惑、与家长的沟通情况及关系等等。收到 信后, 我认真阅读每个人写下的心路历程, 仔细思考了如何解决每个学 生与家庭出现的特殊问题, 然后我再给每个家庭回信, 信中为他们提供
解决问题的各种各样方法! 近期很多家长打来电话、发来微信、短信, 或在钉钉里留言, 分享孩子们通过我的帮助学习状态越来越好, 与家长 的关系越来越融洽, 家庭越来越幸福!

3. 4 开展个体心理咨询

《中小学心理健康教育指导纲要》指出: “进行个别咨询与辅导是心 理健康教育的一条有效途径。” 对于部分有心理障碍的学生, 只能利用心 理咨询或心理治疗的方法解决。在疫情期间, 我首先与有心理障碍的学 生家长进行沟通, 了解学生的表现及问题发生的关键原因, 然后就给学 生打电话发信息进一步深入了解, 最后约见学生面对面谈话, 较好地解 决了一些学生困惑。如学生龚某, 疫情期间与家长多次发生激烈冲突, 几乎放弃学习, 不吃不喝, 把自己反锁在房间里, 几天不出门。家长非 常着急, 打电话求助我, 我和家长沟通多次, 教她如何孩子相处, 如何 引导和激励孩子学习, 如何避免和孩子的冲突; 同时我又和该同学微信、 电话交流, 每次电话通话都是一个多小时, 并多次送她礼物, 帮助孩子 战胜考前心理忧虑症, 让她走出阴䨪, 勇敢的面对高考。

因为我及时给她提供帮助, 答疑解惑, 排解学生的心理困扰, 这个 女孩郁闪的心情变得开心乐观, 被动学习变得积极主动, 与家长的亲子 关系也变得越来越好!

3.5 提出明确学习目标

积极备战高考, 考出理想成绩, 考上理想中的大学, 是每个高三学 生的学习目标。因此, 不论是对学生的心理健康教育与调适, 还是各科 目专业知识的讲授与辅导, 都应该围绕这一目标来进行。因此, 我在主 题班会、线上授课等多种场合, 都注重给学生提出明确的学习目标, 同 时发动各科任教师注重对学习困难学生的及时辅导, 在帮助学生树立信 心的同时, 也给学生以学习上的支持与帮助。我对学生说: “生活给予我 们的苦难終将成为一种深深的印记, 它告诉你, 你确实和别人不一样, 希望你能及时的掌握好学习与生活的节奏, 张弛有度, 希望你能高兴的 接纳自己, 肯定自己优点改正缺点, 希望你能面对镜子里的自己大声对 自己说: ‘我信我行, 我拼我赢!’”

\section{[参考文献]}

[1]梁婷婷.多媒体教学在学生心理健康教育中的运用 [J]. 小学科学 (教师版),2020(09):179.

[2]刘丰林,杜睿,刘义.大学生心理健康与心理发展教育机制探朢[J]. 学校党建与思想教育,2020(18):20-22.

[3]汤媛. 高校大学生心理健康问题及其对策分析[J].教书育人(高教 论坛),2020(27):41-43. 